\title{
IDENTIDADE DO ENSINO MÉDIO NO CONTEXTO DE IMPLEMENTAÇÃO DA REESTRUTURAÇÃO CURRICULAR DA SEDUC/RS: MUDANÇA OU CONTINUIDADE?
}

\author{
L. B. ZAMBON ${ }^{*}$, E. A. TERRAZZAN \\ Universidade Federal de Santa Maria \\ luzambon@gmail.com*
}

Submetido 11/03/2017 - Aceito 27/08/2017

DOI: $10.15628 /$ holos.2017.5755

\section{RESUMO}

Neste artigo, buscamos compreender em que medida o processo de implementação da Proposta de Reestruturação Curricular do Ensino Médio da SEDUC/RS implicou em mudanças na definição da identidade do Ensino Médio. Para tanto, foram realizados 03 grupos focais que envolveram 20 Professores de Seminário Integrado (SI), novo componente curricular do Ensino Médio, e foram realizadas 34 entrevistas que envolveram 13 Coordenadores Pedagógicos, 20 Professores de SI (alguns agrupados) e 06 Professores do Ensino Médio, todos eles atuantes em 20 escolas da região da 8a Coordenadoria Regional de Educação da SEDUC/RS que vivenciaram esse processo de implementação da Proposta. A partir dos resultados, podemos afirmar que a implementação da referida Proposta não modificou substancialmente o Ensino Médio, especialmente porque não suscitou suficientemente o questionamento sobre a função social dessa escola de Ensino Médio, que nesse processo permaneceu como um núcleo sólido, protegido de tal modo que ali não se efetivaram mudanças.

PALAVRAS-CHAVE: Ensino Médio, Políticas Educacionais, Reestruturação Curricular, Identidade do Ensino Médio.

\section{IDENTITY OF HIGH SCHOOL IN THE CONTEXT OF IMPLEMENTATION CURRICULAR RESTRUCTURING OF SEDUC/RS: CHANGE OR CONTINUITY?}

\begin{abstract}
In this paper, we aim to understand if the process of implementation of the proposal for high school curriculum restructuring of SEDUC/RS produced changes in the definition of the identity of High School. We did 03 focus group with 20 teachers of SI and 34 interviews with 13 education coordinators, $20 \mathrm{SI}$ Teachers (some grouped) and 06 high school teachers, acting in 20
\end{abstract}

Schools of the $8^{\text {th }}$ Regional Coordination of Education SEDUC/RS. We can say that the implementation of the proposal did not changed High School, especially because it did not sufficiently raise the question about the social function of this High School, which in that process remained a solid nucleus, protected in such a way that no changes took place there.

KEYWORDS: High School, Educational Policy, Curriculum Restructuring, Identity of High School. 


\section{INTRODUÇÃO}

O Ensino Médio, definido como etapa final da educação básica, no âmbito da atual Lei de Diretrizes e Bases da Educação Nacional (LDB 9.394/96), enfrenta há muitos anos o problema de falta de identidade própria.

Uma retomada sobre a história do Ensino Médio no Brasil nos indica que, no período colonial, o ensino secundário clássico-humanista, fornecido pelos jesuítas, era seletivamente aristocrático e servia para consolidar o status de classe dirigente dos brancos. A expulsão dos jesuítas suplantou seu sistema de ensino, tornando o ensino secundário desestruturado, já que não se constituía num curso seriado e ordenado, mas em matérias avulsas, orientadas para os exames de acesso ao ensino superior.

No Brasil República, propostas de reforma, impostas via decretos, pretenderam mudar esse caráter do ensino secundário, com intuito de organizá-lo como um curso com finalidade mais ampla que a mera função propedêutica que o caracterizava. Essas medidas foram frustradas na medida em que não se superou sua função preparatória.

Até esse período pode-se dizer, então, que a identidade do ensino secundário era de um curso de passagem, elitista, pois frequentado pelos filhos das famílias mais ricas, e propedêutico, pois tinha como finalidade a preparação para o ensino superior.

A partir da década de 1930, o modelo econômico de industrialização e de substituição de importações engendra a demanda por expansão do ensino, a qual foi resolvida pela instauração da dualidade: escola secundária para dirigentes e técnica profissional para formação de mão-deobra. Sua identidade, portanto, também era dual: formação das "elites condutoras", com finalidade de preparação para o ingresso no ensino superior, e formação da classe trabalhadora, com finalidade de preparar os jovens para o trabalho instrumental.

Já na década de 1970, a partir da Lei 5.692/1971, ficou estabelecida a profissionalização compulsória do 2 o grau. Essa proposição, de uma pretensa "escola única" de 2o grau profissionalizante, consistiu em hipocrisia, já que, na verdade, universalizou uma escola de técnicos submissos (Nosella, 2011), ao mesmo tempo em que as escolas tradicionais mantiveram uma preparação para o vestibular, cada vez mais concorrido. A identidade do ensino de $2 \circ$ grau, portanto, manteve sua "esquizofrenia" (Zibas, 1992), preparando alguns para o ensino superior e fornecendo um ensino profissionalizante, agora esvaziado, para os demais.

Na década de 1990, a LDB 9.394/96 definiu o Ensino Médio como etapa final da educação básica, com finalidades de consolidação e aprofundamento dos conhecimentos adquiridos no ensino fundamental, de preparação básica para o trabalho e para a cidadania, de aprimoramento do educando como pessoa humana e de compreensão dos fundamentos científico-tecnológicos dos processos produtivos.

Porém, como nos alerta Nosella (2011), o amplo conceito de cidadania abriga várias posições, permitindo que cada grupo social fique com a sua prática. Além disso, a tese da inclusão excludente denuncia estratégias de inclusão nos diversos níveis e modalidades da educação escolar sem padrão de qualidade, que confere uma "certificação vazia", apontando 
uma aparente inclusão que fornecerá a justificativa, pela incompetência, para a exclusão do mundo do trabalho, dos direitos e das formas dignas de existência (Kuenzer, 2005).

A identidade do Ensino Médio brasileiro, portanto, não está constituída. Temos vários "Ensinos Médios" sendo desenvolvidos nas redes escolares públicas e privadas, os quais produzem desigualdades educacionais e aprofundam desigualdades sociais, constituindo-se, então, como dispositivo de diferenciação social.

Diante desse contexto, podemos identificar como desafios para o Ensino Médio no Brasil, além da necessidade ainda premente de acesso a essa etapa de escolaridade para todos os brasileiros, a garantia da permanência dos estudantes no Ensino Médio, acompanhada de uma aprendizagem significativa dos elementos conceituais selecionados em cada área disciplinar. Além disso, é preciso superar a finalidade meramente preparatória para ingresso no ensino superior, mediante elaboração de propostas que, de fato, atendam às necessidades de preparação dos jovens para uma participação crítica e responsável.

Neste sentido, situamos a Proposta de Reestruturação Curricular do Ensino Médio da SEDUC/RS, implementada nas escolas da Rede Escolar Pública Estadual do RS, no âmbito da gestão 2011-2014.

Na prática, a partir da implementação dessa proposta, foi estabelecida uma ampliação da carga horária para o Ensino Médio, passando de 800h (carga horária mínima anual instituída pela LDB) para 1000h anuais. Em termos de carga horária semanal, fixaram-se 30 horas-aula, ao invés das 25 horas-aula antes previstas. Foi proposta, também, uma reorganização curricular, incorporando à formação geral (quatro áreas de conhecimento: Linguagens, Matemática, Ciências da Natureza e Ciências Humanas) uma parte diversificada, composta de duas Línguas Estrangeiras Modernas, Ensino Religioso e dos denominados "Seminários Integrados (SI)", novo componente da grade curricular do Ensino Médio, que possuía uma carga horária semanal de 3 horas-aula, nos quais se propunha a realização de projetos de pesquisa escolar. Além disso, mudanças na avaliação da aprendizagem dos alunos foram propostas, especificamente, no que se refere à expressão dos resultados do desempenho dos alunos, que passou a ser realizada por conceitos e por área curricular ${ }^{1}$.

Diante do contexto de implementação dessa Proposta, realizamos uma pesquisa que objetivou compreender os processos de organização e de desenvolvimento do trabalho escolar em Escolas de Ensino Médio pertencentes à abrangência da 8 $^{a}$ Coordenadoria Regional de Educação (8aCRE), instância político-administrativa da SEDUC/RS (Zambon, 2015).

Essa pesquisa ancorou-se na compreensão de que as políticas educacionais não são estáticas, mas caracterizam-se como um processo que envolve múltiplos espaços e sujeitos: a proposição das políticas, a elaboração de compreensão sobre seus significados, a interpretação e adaptação, em cada contexto escolar, das suas proposições, e a incorporação ou não dessas proposições nas práticas escolares.

Então, embasamos nossa compreensão no entendimento de que uma política envolve sempre um processo com diferentes dimensões. E, para tanto, apoiamo-nos nas proposições de autores que enfatizam o caráter processual das políticas, dentre os quais, destacam-se Stephen J.

\footnotetext{
${ }^{1} \mathrm{O}$ documento completo dessa Proposta está disponível para ser acessado no endereço <http://www.educacao.rs.gov.br/dados/ens_med_proposta.pdf>.
} 
Ball e colaboradores. A "abordagem do ciclo de políticas", por eles proposta, considera importante analisar e relacionar diversos contextos envolvidos no processo de desenvolvimento de uma política educacional: (1) contexto de influência, espaço onde os discursos políticos são construídos, (2) contexto de produção de texto, resultado de disputas e acordos, (3) contexto de prática, onde ocorre a implementação da política, ou no qual a política produz efeitos e consequências, sendo que esses podem resultar em transformações das proposições iniciais (Mainardes, 2006).

A partir da noção de recontextualização, proposta por Basil Bernstein (1996), assumimos como pressupostos que, uma vez apresentada a Proposta de Reestruturação Curricular do Ensino Médio pela SEDUC/RS, a transferência do contexto oficial para o escolar significou um processo de negociações, aceitação, rejeição, reinterpretação e produção de significados próprios pelos sujeitos de cada escola. Assumimos também que as prescrições e orientações da proposta não se efetivam no contexto da prática de forma espelhada; porém, ainda que não produzam alterações na totalidade das práticas escolares, repercutem no âmbito escolar, produzindo alterações e imprimindo novos códigos à cultura escolar (Silva, 2014).

Neste artigo, que se constitui como recorte dessa pesquisa mais ampla, buscamos compreender em que medida o processo de implementação da Proposta de Reestruturação Curricular do Ensino Médio da SEDUC/RS implicou em mudanças na definição da identidade do Ensino Médio.

\section{PROCEDIMENTOS METODOLÓGICOS}

Para atender esse objetivo, utilizamos fontes de informação de dois tipos: (1) sujeitos, a saber: professores do Ensino Médio, professores responsáveis por turmas de SI e membros da equipe de coordenação pedagógica e (2) documentos, a saber: documento de apresentação da proposta pela SEDUC/RS, intitulado "Proposta Pedagógica para o Ensino Médio Politécnico e Educação Profissional Integrada ao Ensino Médio - 2011-2014" (Rio Grande do Sul, 2011), e "Regimento Escolar padrão para o Ensino Médio Politécnico" (Rio Grande do Sul, 2012), elaborado pela secretaria e aprovado pelo Conselho Estadual de Educação (parecer 310/2012). Os instrumentos de coleta de informação utilizados foram grupos focais e entrevistas com os sujeitos e roteiro para análise textual dos documentos.

Os grupos focais foram realizados no ano de 2013 com professores responsáveis por turmas de Seminário Integrado. Como critério para definição dos professores a serem convidados, selecionamos como universo potencial os participantes da "1a Mostra do Ensino Médio Politécnico: Experiências do Seminário Integrado nas escolas da 8a CRE", promovida pela $8^{a}$ CRE/SEDUC/RS e realizada entre os dias 23 e 25 de maio de 2013 . No total, 27 escolas pertencentes à abrangência da 8 a CRE/SEDUC/RS participaram da Mostra. Enviamos convites, por correio eletrônico, para os professores participantes, com o cuidado de convidar um professor por escola. No total, foram realizados 03 grupos focais, com a participação de 20 Professores de SI, atuantes em 20 escolas da região da 8ạR/SEDUC/RS.

Depois de realizadas análises parciais das informações coletadas nos grupos focais, buscamos aprofundar a coleta mediante a realização de entrevistas nessas 20 escolas. Assim, no 
ano de 2014, realizamos 34 entrevistas, sendo 06 entrevistas com professores do Ensino Médio, 15 com professores de Seminário Integrado e 13 entrevistas com coordenadores pedagógicos.

Já o roteiro para análise dos documentos foi organizado como um Quadro DescritivoAnalítico que articula as informações coletadas nos documentos com aquelas coletadas mediante grupo focal e entrevista, tendo em vista que nosso interesse foi estabelecer aproximações e afastamentos entre "ações realizadas nas escolas" e "prescrições/orientações presentes nos documentos".

Para proceder ao tratamento e análise das informações coletadas, utilizamos a técnica da categorização temática (Gibbs, 2009; Charmaz, 2009) e estabelecemos categorias de análise $a$ posteriori, ou seja, como resultado de várias leituras das informações.

\section{RESULTADOS E DISCUSSÃO}

Nesta seção, apresentamos uma parte dos resultados construídos a partir de nossa pesquisa (Zambon, 2015), focalizando a discussão sobre a identidade do Ensino Médio, no âmbito do processo de implementação da Proposta de Reestruturação Curricular do Ensino Médio da SEDUC/RS.

Um dos aspectos analisados referiu-se às ações desenvolvidas nas escolas investigadas para implementação da Proposta. Nossa primeira expectativa era identificar ações institucionais e coletivas realizadas pelas escolas; contudo, constatamos que ações desse tipo, envolvendo todos os professores, foram praticamente inexistentes, visto que a implementação da proposta implicou diferentes níveis de assimilação e de envolvimento por parte dos professores. Dentre as ações identificadas, a categoria mais recorrente foi aquela relativa às ações diretamente relacionadas ao Seminário Integrado (SI), novo componente da matriz curricular do Ensino Médio. O detalhamento dessa categoria revela que apenas um conjunto dos professores esteve envolvido com essa ação, quais sejam, os membros da coordenação pedagógica e os professores que assumiram turmas de SI em cada série do Ensino Médio. Porém, a inclusão dessa ação afetou pouco o trabalho realizado pelos demais professores, que tiveram um envolvimento pouco significativo com as atividades realizadas no âmbito dos Seminários Integrados.

Assim, uma parte significativa das ações realizadas nas escolas para implementação da Proposta de Reestruturação Curricular do Ensino Médio foi realizada exclusivamente por uma pequena parcela do coletivo de professores dessas escolas. Portanto, podemos afirmar que enquanto houve modificação do trabalho realizado em uma parte do Ensino Médio particularmente aquele realizado no âmbito do componente curricular "SI" - outra parte continuou sendo realizada com poucas alterações - a dos demais componentes curriculares.

A partir das análises realizadas, constatamos que a resistência de alguns professores, pais e alunos às mudanças propostas na matriz curricular do Ensino Médio, no âmbito do processo de implementação da Proposta de Reestruturação Curricular do Ensino Médio da SEDUC/RS, motivada pelo desejo de manutenção da função propedêutica dessa etapa da escolaridade, implicou na pouca aceitação, e até mesmo em uma rejeição em muitos casos, do Seminário 
Integrado. Isso levou o SI a permanecer inserido na matriz curricular do Ensino Médio com uma legitimidade bastante frágil, como sugerem os depoimentos abaixo ${ }^{2}$ :

com relação a essas mudanças do Ensino Médio, uma das coisas que eles [os alunos] nos cobram muito é o porquê do seminário [integrado]... porque eles queriam muitas vezes conteúdo e conteúdo (E19-PEM)

pra eles [os alunos], eles acham [SI] uma perda de tempo, que eles gostariam de ta aprendendo matemática, química, física, biologia (...), focado pro vestibular, sabe? (E10CP)

os colegas [professores] que estavam sempre na sala de aula [ou seja, que não assumiram SI] diziam: "isso aí é só matação de aula! Isso aí.... isso aí é só pra matar aula, isso aí não sei o que". (E01-PSI1)

Trata-se, nesses discursos, da defesa de uma perspectiva de formação unilateral e propedêutica do Ensino Médio que está enraizada na cultura escolar em nossa região, como de resto no país em geral:

a escola sempre foi muito atrelada ao currículo da universidade, do PS [processo seletivo seriado/UFSM] e vestibular e isso é uma coisa assim muito enraizada, muito difícil pra gente trabalhar com isso (...). (E11-CP)

É importante mencionar que essa resistência às mudanças propostas na matriz curricular do Ensino Médio, se manifestou, muitas vezes, de forma oculta; ou seja, por trás de um discurso que incorpora a ideia de uma formação integral no Ensino Médio, existiam manifestações, ações realizadas, estratégias utilizadas para, na verdade, manter o Ensino Médio propedêutico. Particularmente em relação à inclusão dos Seminários Integrados, percebemos que a própria organização da grade de horários das disciplinas consistiu em indicador que reflete a forma como a escola percebe a relevância de cada componente curricular:

\begin{abstract}
a própria direção da escola, e tudo mais, quando tem momentos pra ensaiar um teatro e não sei o que mais, é no dia do seminário integrado né, eles pedem esse momento, aí você percebe a valorização que dão pro seminário! (E03-PSI1)

os horários que a escola também nos encaixa na disciplina de seminário integrado, facilita, pra que o aluno, às vezes, não assista a aula, às vezes, nós temos, por exemplo, uma aula de seminário integrado no ultimo período de sexta-feira [noturno], ou duas aulas de seminário integrado após o recreio. O que acontece? esses alunos já são maiores de 18 anos, eles não acham tanta importância, porque eles já tem a opinião deles formada, aquela coisa assim, e eles não assistem as aulas. (E08-PSI1)
\end{abstract}

Quanto à organização dos Seminários Integrados, encontramos no documento de apresentação da Proposta de Reestruturação Curricular do Ensino Médio da SEDUC/RS, que a coordenação dos trabalhos de SI deveria ser do coletivo dos professores e exercitada de forma rotativa para oportunizar que todos se apropriassem e compartilhassem do processo de construção da organização curricular (Rio Grande do Sul, 2011). Porém, as contingências para a implantação do SI, em termos administrativos, exigiram que tal espaço fosse incluído formalmente como uma "disciplina escolar", ou seja, sob a responsabilidade de um único professor em cada turma de Ensino Médio, cada professor podendo assumir, no máximo 6 horasaula de SI em cada escola, equivalente a duas turmas.

Além disso, esse documento caracteriza o Seminário Integrado, o qual consta na carga horária da parte diversificada do currículo proposto, como espaço para realizar a articulação dos

\footnotetext{
2 Para preservar a identidade dos sujeitos, utilizamos um código como identificador, sendo "E"- código da escola, "CP"- Coordenador Pedagógico, "PSI"- Professor responsável por SI, "PEM"- Professor de Ensino Médio.
} 
dois "blocos do currículo": formação geral e parte diversificada. Porém, essa divisão - formação geral, parte diversificada - tornou-se, na prática, uma organização apenas formal e acabou sendo transformada em outra: "Seminário Integrado" de um lado e demais disciplinas do currículo de outro. Formalizada tal divisão, o papel do seminário como articulador também se perdeu.

A partir desse movimento, consolidou-se, então, uma forma de trabalho que "no lado" das disciplinas, basicamente, foi uma continuidade do que acontecia no Ensino Médio tradicional, caracterizada pelo trabalho disciplinar, com poucas articulações nas áreas e entre as áreas. Constatamos, no contexto investigado, que as articulações, quando ocorriam, se davam mediante realização de projetos planejados e desenvolvidos conjuntamente por professores de uma mesma área curricular; porém, com caráter adicional (pois se somavam ao trabalho realizado por cada professor em sua disciplina) e com duração bem determinada. Na "parte diversificada" consolidou-se o desenvolvimento de projetos de pesquisa escolar no âmbito do Seminário Integrado.

O depoimento abaixo, de uma coordenadora pedagógica, sintetiza esses aspectos:

a professora de seminário acaba conversando com os [demais] professores nos
corredores, porque nós não conseguimos organizar esse espaço. Teoricamente a
proposta é legal e os professores gostam também; mas, assim ó: a estrutura da escola
não permite. E não é falta de vontade nossa aqui de organizar, sabe? Que a gente até
tenta, mas é em função da estrutura, do número de horas dos professores, enfim... O
seminário integrado, na verdade, ele não funciona como ele deveria, tá? Porque às
vezes, a gente nem consegue reunir os professores, e ai o professor tem que... a
professora acaba tendo que trabalhar sozinha, ela fica uma disciplina... acaba ficando
uma disciplina a mais e não tão integrada. (E11-CP)

O "engessamento" do sistema, portanto, acabou favorecendo uma ressignificação do SI: de espaço proposto para enfrentar uma organização rigorosamente disciplinar do currículo do Ensino Médio, acabou ele próprio constituindo-se como disciplina isolada. É claro que para consolidar tal ressignificação diversos fatores colaboraram, conforme nossa análise evidenciou: as contingências do sistema, as resistências para mudanças na estrutura curricular do Ensino Médio, a falta de compreensão sobre o papel do SI, a formação precária fornecida pela SEDUC/RS, insuficiente para garantir tal compreensão, as dificuldades para organização e realização de encontros entre o coletivo de professores para planejamento conjunto das atividades de $\mathrm{SI}$, as resistências de professores à realização de trabalho coletivo.

Assim é que os trabalhos de SI acabaram se efetivando com pouca ou nenhuma articulação com as áreas curriculares. Portanto, consolidou-se a seguinte realidade: o $\mathrm{SI}$ e as demais disciplinas ocorreram basicamente paralelos um ao outro, ou seja, sem cruzamento, sem ponto comum.

O Seminário Integrado se constituiu, então, no contexto da prática como "disciplina". Mais que isso, uma disciplina isolada das demais, que constantemente foi questionada quanto à sua finalidade na matriz curricular do Ensino Médio. Foi comum, nas nossas análises, a identificação de adjetivos atribuídos, segundo depoimentos, por alguns pais, alguns alunos e alguns professores, ao Seminário Integrado, caracterizando-o como atividade que "não serve para nada", que "não vai levar a nada", que "é perda de tempo", que é "encheção de linguiça", que é "matação". Essas afirmações podem ser exploradas no sentido inverso: se seminário "não serve para nada", é de se supor que, desse ponto de vista, os demais componentes curriculares servem. Mas, a questão que levantamos é: servem para quê? Que critério estaria sendo utilizado, 
subjacente a essas manifestações, para essa classificação? Lamentavelmente, o que parece estar sendo considerado é, basicamente, um critério utilitarista que defende a função propedêutica do Ensino Médio, ou seja, de preparação para a continuidade dos estudos.

Como disciplina - e, mais que isso, como uma disciplina isolada - o Seminário Integrado foi desenvolvido nas escolas como a "parte estranha" do Ensino Médio, na medida em que o trabalho ali realizado distanciava-se, em geral, da forma comumente característica de realização das demais disciplinas, principalmente em relação à forma que privilegia quantidade de conteúdo sobre qualidade, que se preocupa em "vencer" conteúdo a qualquer custo.

Essa situação parece sinalizar a coexistência de "duas escolas" com propósitos absolutamente diferentes, que conviveram ambas em cada unidade escolar: uma que, essencialmente, continuou trabalhando em favor de uma formação unilateral dos jovens, mediante um ensino meramente enciclopédico dos conteúdos relativos às estruturas conceituais das áreas disciplinares; e outra que, claramente, começou a preocupar-se com uma formação mais ampla, integral dos jovens.

\begin{abstract}
a maioria [dos professores] continua fazendo as mesmas coisas em sala de aula, mesma aula, do mesmo jeito de conduzir, de avaliar, e [por outro lado] temos o seminário, (...) o menino se torna mais livre ali, no seminário ele senta do jeito que ele quer, ele "pá, pá" vai lá e faz (...). (E12-PSI2)
\end{abstract}

A "primeira escola" se desenvolveu no âmbito dos tradicionais componentes curriculares do Ensino Médio (quando realizados nesse sentido "tradicional"). A "segunda escola" restringiuse ao espaço destinado ao componente curricular Seminário Integrado.

De um lado, o Seminário Integrado trouxe para o currículo do Ensino Médio uma perspectiva de formação mais integral dos jovens. Porém, o currículo realizado na "outra parte" do Ensino Médio, em geral, reduziu a formação humana integral à dimensão da continuidade dos estudos, oferecendo um ensino baseado em um "academicismo elitista e descomprometido para não dizer, indiferente - às ocorrências no mundo do trabalho" (Oliveira, 2009, p.145).

\title{
4 CONCLUSÕES
}

A partir desses resultados, podemos afirmar que a Proposta de Reestruturação Curricular do Ensino Médio da SEDUC/RS não modificou substancialmente sua identidade, especialmente porque não suscitou suficientemente o questionamento sobre a função social da escola de Ensino Médio, que nesse processo permaneceu como um núcleo sólido (Thurler, 2001), protegido de tal modo que ali não se efetivaram mudanças.

Portanto, o Ensino Médio, no âmbito do processo de implementação da Proposta da SEDUC/RS, manteve sua função propedêutica, oferecendo a preparação para ingresso no Ensino Superior para aqueles alunos que buscavam essa preparação, ainda que os "obrigou" a participar, em uma pequena parte da semana, das atividades de Seminário Integrado, atividades que, desse ponto de vista propedêutico, foram consideradas "inúteis" para a preparação esperada. Para os demais alunos, mascarou a "inutilidade" da "parte majoritária" do Ensino Médio realizado, oferecendo, mediante o trabalho do Seminário Integrado, atividades que foram qualificadas com adjetivos como "diferentes", "práticas", "mais interessantes" e que fogem à rotina massacrante do ensino enciclopédico, dirigido para a prática da chamada "decoreba". 
Assim, a proposta de um Ensino Médio Politécnico, apresentada pela SEDUC/RS, pelas condições efetivas que encontrou na prática, parece ter estabelecido um Ensino Médio duplamente adjetivado: "Politécnico/propedêutico". O primeiro adjetivo estava formalmente documentado; contudo, o segundo adjetivo prevaleceu no Ensino Médio efetivamente praticado.

\section{REFERÊNCIAS}

Bernstein, B. (1996). A estruturação do discurso pedagógico: classe, código e controle. (2a ed.). (T. T. da Silva \& L. F. G. Pereira, Trad.). Petrópolis: Vozes. (Obra original publicada em 1990).

Charmaz, K. (2009). A construção da teoria fundamentada: guia prático para análise qualitativa. (J. E. Costa, Trad.). (Coleção "Métodos e Pesquisa"). Porto Alegre: Artmed. (Obra original publicada em 2006).

Gibbs, G. (2009). Análise de dados qualitativos. (R. C. Costa, Trad.). Porto Alegre: Artmed. (Obra original publicada em 2008).

Kuenzer, A. Z. (2005). Exclusão includente e inclusão excludente: a nova forma de dualidade estrutural que objetiva as novas relações entre educação e trabalho. In D. Saviani, J. L. Sanfelice \& J. C. Lombardi (Orgs.). Capitalismo, trabalho e educação. (3a ed.). Campinas: Autores Associados.

Mainardes, J. (2006). Abordagem do ciclo de políticas: Uma contribuição para a análise de Políticas Educacionais. Educação \& Sociedade, 27(94), 47-69.

Nosella, P. (2011). Ensino médio: em busca do princípio pedagógico. Educação e Sociedade, 32(117), 1051-1066.

Oliveira, R. (2009). A possibilidade da escola unitária na sociedade capitalista. Cadernos de Educação, 32, 141-160.

Parecer n. 310, de 04 de abril de 2012 (2012). Aprova o Regimento Escolar Padrão para o ensino médio "politécnico" a ser adotado por escolas da Rede Pública Estadual que solicitarem credenciamento e autorização para funcionamento desse curso a partir do ano letivo de 2012. Porto Alegre, RS. Recuperado em 28 de junho de 2012, de http://www.ceed.rs.gov.br/download/1334679658pare_0310.pdf

Rio Grande do Sul, Secretaria da Educação (2011). Proposta pedagógica para o ensino médio politécnico e educação profissional integrada ao ensino médio 2011-2014. Porto Alegre, RS Recuperado em 28 de junho de 2012, de http://www.educacao.rs.gov.br/dados/ens_med_proposta.pdf

Silva, M. R. (2014). Perspectiva analítica para o estudo das políticas curriculares: processos de recontextualização. Anais da Jornada da Rede Latino Americana de Estudos Epistemológicos em Políticas Educacionais, Curitiba, PR, Brasil, 2.

Thurler, M. G. (2001). Inovar no interior da escola. (J. Wolff, Trad.). Porto Alegre: Artmed. (Obra original publicada em 1998).

Zibas, D. L. (1992). Ser ou não ser: o debate sobre o ensino médio. Cadernos de Pesquisa , 80, 5661.

Zambon, L. B. (2015). Organização e desenvolvimento do trabalho escolar no contexto de implementação da proposta de reestruturação curricular do Ensino Médio da SEDUC/RS. Tese de Doutorado, Universidade Federal de Santa Maria, Santa Maria, RS, Brasil. 